\title{
NIPPLE RECONSTRUCTION USING THE C-V FLAP TECHNIQUE: LONG-TERM OUTCOMES
}

\author{
Lona Jalini*,1, Jonathan Lund* and Vijay Kurup* \\ *North Tees and Hartlepool University Hospital NHS Foundation Trust,UK.
}

\begin{abstract}
Introduction: Nipple creation using the $\mathrm{C}-\mathrm{V}$ flap technique is often the final step in breast reconstruction. The aim of this study was to assess subjectively and objectively the cosmetic outcomes and satisfaction of patients undergoing C-V flap nipple reconstruction. Methods: Subjective assessments of patient satisfaction with the neo-nipple recorded by visual analogue scoring (VAS; 0-10). Objective measurements were performed using a calliper to measure nipple projection relative to the native breast. Descriptive data analysis was performed with differences in projection assessed with the Mann-Whitney test and mean and median VAS scores (with inter-quartile ranges; IQR) calculated to describe satisfaction. Results: Thirty-three C-V flap nipple reconstructions performed. 87.9\% received latissimus dorsi (LD) reconstructions with implants, and $12.1 \%$ had transverse rectus abdominis muscle (TRAM) reconstructions. The median projection of reconstructed nipples was $4.7 \mathrm{~mm}$ (range 4-10.2 $\mathrm{mm}$ ) at 4.6 years mean follow-up, which was not significantly different from the contralateral nipple $(\mathrm{p}=0.34)$. Patient satisfaction was 9 (IQR: 8-10) with shape, 9 (IQR: 7.5-10) with projection, 5 (IQR: 2-9.6) with sensation, and 8.5 (IQR: 6-9.5) with symmetry. Median overall satisfaction was 9 (IQR: 8-10). Three patients had complete nipple loss, of whom two had undergone nipple piercing post procedure, and none had received radiotherapy. Conclusion: $\mathrm{C}-\mathrm{V}$ flap nipple reconstruction provides a straightforward and reliable method to reconstruct the nipple that enhances confidence and perception of body image. Satisfaction was high with long-term outcomes and in terms of projection equivalent to the contralateral breast.
\end{abstract}

KEYWORDS: C-V flap; nipple reconstruction; patient satisfaction

\section{Introduction}

Nipple reconstruction is the final phase of the long journey of breast reconstruction. When performed well, the patient can finally experience and view the reconstructed breast as normal [1]. Nipple reconstruction is often combined with tattooing to

Copyright (c) 2016 by the Bulgarian Association of Young Surgeons

DOI:10.5455/ijsm.nipplereconstruction

First Received: February 17, 2016

Accepted: March 31, 2016

Manuscript Associate Editor: George Baitchev (BG)

Editor-in Chief: Ivan Inkov (BG)

Reviewers: Andrea Sisti (IT)

${ }^{1}$ Lona Jalini, North Tees and Hartlepool University Hospital NHS Foundation Trust,UK.

Email: Ionajalini@aol.com simulate not only areolar colour but also to camouflage the scar. However, tattooing is not always necessary, and some women decide to undergo nipple reconstruction without tattooing and vice versa.

One challenge in nipple reconstruction is to produce a threedimensional structure from a two-dimensional surface [1]. Two basic methods are used to achieve this: first, reconstruction using the local flap with or without tattooing or skin grafting from various donor sites (e.g., the inner thigh or buttock crease), and second, the free nipple graft, which is a composite flap using cartilage from another part of the body [2], filler material (e.g., AlloDerm, Radiesse) [3], or tissue from the contralateral breast (the so-called 'nipple sharing' technique). The general principles of nipple-areolar complex reconstruction including the composite nipple graft, local flaps with autologous, alloplastic, or allograft augmentation, and areolar reconstruction using tattooing or skin grafting are reviewed in Nimboriboonporn et 


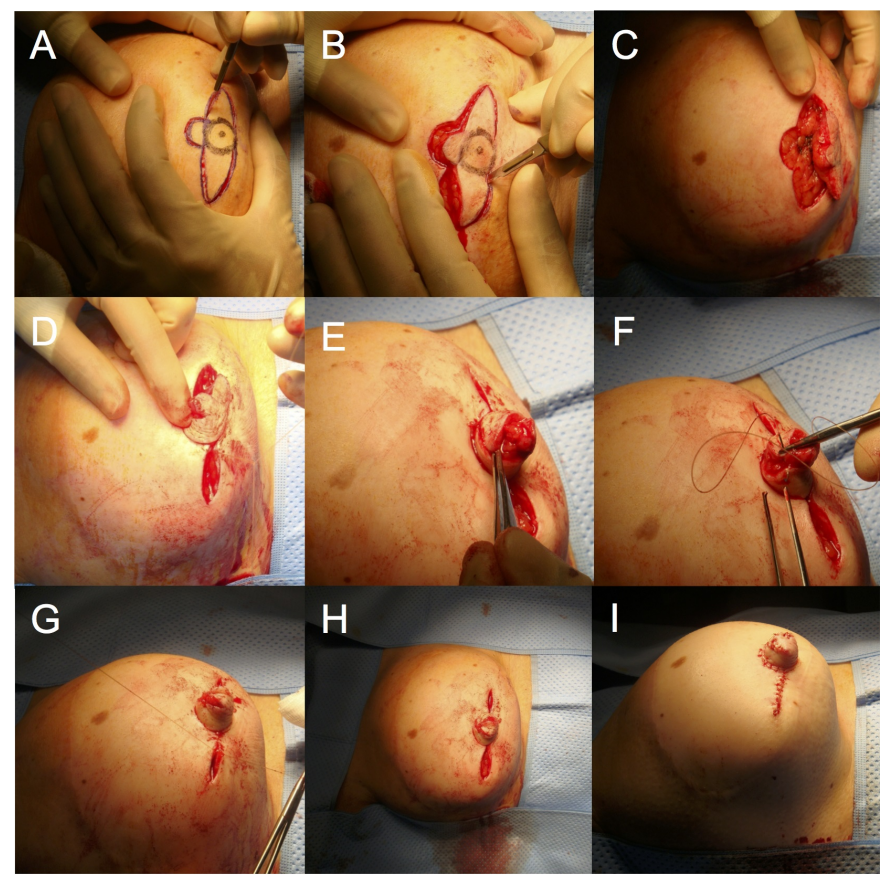

Figure 1: (A-I) The operative C-V flap technique according to Jones [4].

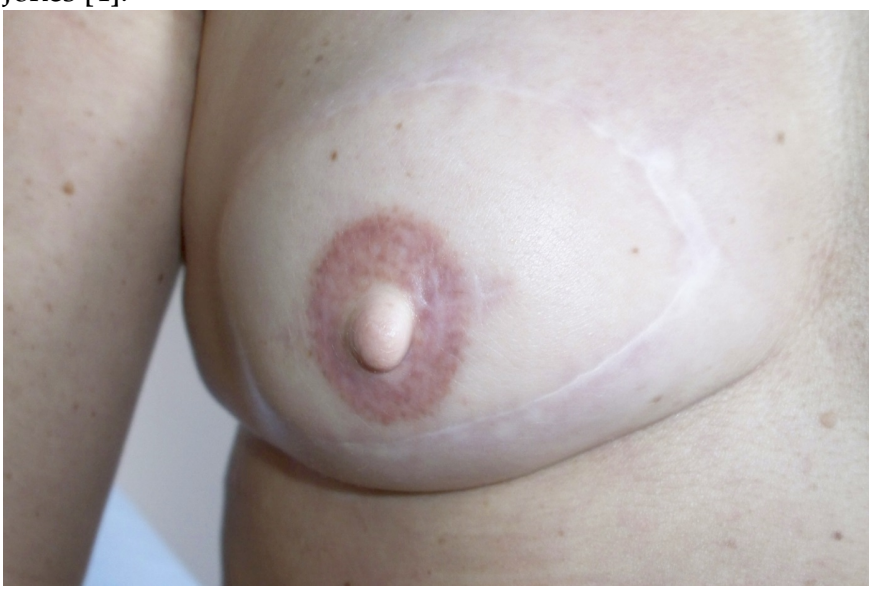

Figure 2: Reconstructed nipple with areolar tattooing 34-months post-operatively.

\section{al. [4].}

All techniques used in nipple reconstruction suffer from some loss of projection over time as part of the regular healing process and formation of scar contracture [3,4]. The C-V flap was first described by Jones et al. in 1994 [5] and offers a simple but reliable nipple reconstruction method that can quickly be learned and performed under local or general anaesthesia with or without tattooing eight to twelve weeks after cancer surgery. The procedure associated with real satisfaction rates and a positive impact on body image and confidence [6]. Complications include bruising, infection, delayed wound healing, and, most severely but rarely, complete or partial nipple loss. In a comprehensive review of the literature comparing different methods of nipple areolar reconstruction, Sisti et al. [7] reported that the most frequent nipple reconstruction technique was the local flap and that there was no significant difference in complication rates between different techniques. Although the loss of projection was noted to be considerable $(45 \%-75 \%)$, it did not have a significant impact on patient satisfaction. They advised that due to contraction, overcorrection of between $25-50 \%$ of the desired result is appropriate when using local flaps to prevent loss of projection. The use of flaps with autologous graft/alloplastic/allograft augmentation showed a minor loss of nipple projection and a relatively high frequency of postoperative flap necrosis [7]. Similarly, Winocour et al. [8] compared the efficacy, projection, and complication rates of different materials used in nipple reconstruction and concluded that there was heterogeneity in the type of equipment used within each category and that inconsistent methodology used for outcome assessment in nipple reconstruction. Synthetic materials showed higher complication rates and allogeneic grafts had nipple projections comparable to those of autologous grafts [8]. The aim of this study was to assess objectively and subjectively the cosmetic outcomes and satisfaction of patients undergoing $\mathrm{C}-\mathrm{V}$ flap nipple reconstruction under the care of a single oncoplastic breast surgeon at a screening unit for service modification and improvement.

\section{Methods}

All patients undergoing C-V flap nipple reconstruction under the care of V.K. between 2006 and 2015 identified from the hospital breast cancer database. There were no exclusion criteria. Case notes were retrieved and demographic information including age, date of surgery, past medical history, smoking history, type of breast reconstruction, symmetrizing procedure, pre- or postoperative radiotherapy, and complications documented.

Subjective assessments were made using a questionnaire focusing primarily on patient satisfaction. Visual analogue scoring (VAS) from 0 to 10 (with 0 as the worst and ten as the best possible outcome) was used to record patient satisfaction with projection, sensation, symmetry, and willingness to recommend the procedure to other women. Objective measurements were made using a calliper to measure the nipple projection in relation to the native breast. The Mann-Whitney U-test was used to test for differences in projection between the reconstructed nipple and contralateral nipple; a p-value $\leq 0.05$ was regarded as significant. VAS scores were analysed to determine the mean and median satisfaction with inter-quartile ranges (IQR). Ethical approval was not required for this study since this was a review of service provision, but all patients verbally consented to participate.

\section{Operative Technique}

All patients were marked sitting upright. The position of the $\mathrm{C}-\mathrm{V}$ flap was marked in relation to the nipple position in the native breast and whether a symmetrizing procedure planned on the contralateral side. The flap was marked to ensure that the blood supply was away from any old scar. The flap was designed one and a half to twice the size of the contralateral nipple to allow for $50 \%$ shrinkage or reduction in projection occurring over time due to absorption of the central fat core to optimise the long-term cosmesis. The procedure was carried out under general anaesthesia.

The design of the flap is shown in Figure 1 and was primarily performed according to Jones et al. [4]. Flaps were composed of two lateral V flaps and a central C-shaped flap: the diameter of the central C-shaped flap determined the diameter of the new nipple while the projection identified by the width of the $\mathrm{V}$ flaps. The base of the $\mathrm{C}$-shaped dermal flap remained attached since the blood supply is derived from the sub-dermal 
plexus from the unincised portion of skin. The $\mathrm{V}$ flaps were elevated from the underlying subcutaneous tissue and wrapped around and sutured to the central C flap with 4-0 Monocryl (Ethicon, Johnson, and Johnson, New Brunswick, NJ). The V-flap donor sites were then closed with non-absorbable 4-0 nylon interrupted sutures. Some authors [1] suggest a protective shield filled with antibiotic ointment or an eye bubble for two weeks post-operatively while others use Lyofoam circles for a further four weeks to protect the new nipple [6]. We chose to apply waterproof, non-crushing adhesive dressing with a window to allow inspection of the viability of the reconstructed nipple. The dressing was left undisturbed for two weeks for post-operative protection. Our unit routinely offers areolar tattooing (carried out by specialist nurse practitioners) 3-6 months postoperatively for those wishing to achieve areolar pigmentation. An example of post-operative result with areolar tattooing is shown in Figure 2. The latter was taken 34 months post-operatively.

\section{Results}

Thirty-two women underwent $33 \mathrm{C}-\mathrm{V}$ flap nipple reconstructions in our unit between 2006 and 2015. All patients attended the clinic for measurements to compare nipple projection in both breasts. Patient demographics are shown in Table 1.

The mean age of reconstruction was 53.5 years (median 52 years, range 40-67 years). Mean and median follow-ups were 4.6 and four years, respectively (range 3-108 months). No patient was a smoker or diabetic at the time of surgery. Twenty-nine patients $(87.9 \%)$ had latissimus dorsi (LD) reconstructions with implants, and four $(12.1 \%)$ had transverse rectus abdominis muscle (TRAM) reconstructions. Seven $(21.2 \%)$ had radiotherapy before nipple reconstruction. A total of nine patients $(27.3 \%)$ had a contralateral breast reduction or mastopexy 12-18 months after nipple reconstruction. Of the thirty-three cases, twenty-one $(63.6 \%)$ patients requested areolar tattooing post-operatively, and none claimed areolar grafting. The median projection of the C-V flap was $4.7 \mathrm{~mm}$ (range $4-10.2 \mathrm{~mm}$ ) with thirteen patients having nipple projection of greater than $4.2 \mathrm{~mm}$ at 4.6 years mean follow-up. The overall difference in projection between the flap and contralateral side was not statistically significant $(\mathrm{p}=0.34)$.Patients reported a mean VAS of 8.3 and median of 9 (IQR: 8-10) with shape, a mean of 8.1 and median of 9 (IQR: 7.5-10) with projection, an average of 5.4 and median of 5 (IQR: 2-9.5) with sensation, and a mean of 7.3 and median of 8.5 (IQR: 6-9.5) with symmetry. Mean overall satisfaction was 8.2 with a median of 9 (IQR: 8-10). Eighty-nine per cent of women were happy to recommend the procedure to other women (Table 2). Twenty-one women were completely satisfied with all aspects of their care including surgery while the remainder (eleven in total) raised various concerns (Table 3). Regarding clinical outcomes, partial ischemic necrosis occurred in seven (21.2\%) patients, of whom three experienced complete nipple loss. None had received radiotherapy, but two women with complete nipple loss underwent nipple piercing against medical advice.

\section{Discussion}

Although a number of nipple reconstruction procedures are described in the literature, few clinical trials have been conducted to reach a consensus on a favoured method regarding long-term cosmesis and ease of the technique. In practice, the chosen method is usually dependent on the experience of the individual surgeon and patient choice. Nipple reconstruction with or without areola tattooing is the finishing touch and the defining feature of the female breast [10]. Some studies have shown that timely reconstruction led to improved psychological well-being in the patient and improved patient and partner satisfaction [11, 8]. Regardless of the technique employed, certain rules are followed to achieve a successful local flap reconstruction including leaving a broad enough pedicle to ensure adequate blood supply while detaching it from surrounding tissue to allow flap shaping Most reconstructed nipples retract over time due to scarring and scar contraction, particularly when there has been previous radiotherapy, infection, or poor flap design that compromises the circulation and delays healing. Well, established flaps include the skate [12], star [13], double-opposing tab flap [14-16], double opposing V-Y flap [17], and the V-Y advancement flap [18]. In exceptional circumstances in which the nipple entirely or partially destroyed secondary to burns, a modified fish-tail flap has been described for nipple reconstruction with good term long-term results [18].

However, since its introduction in 1994 [5], the C-V flap has been shown to be a successful method, albeit with a variable rate of patient satisfaction ranging from low to high $[5,19]$. The most common dissatisfaction with nipple reconstruction is flattening and loss of projection over time followed by colour mismatch, shape, size, and malposition [20]. Here we report a high satisfaction rate with shape (median VAS 9) and symmetry (median VAS 8.5), with the majority of patients feeling more confident about their body image. Only one patient reported tattoo fading, but this was three years post procedure. Another patient reported intractable itching eighteen months post procedure. Patients informed at the time of surgery that nipple reconstruction cannot fully restore normal sensation, reflected in a median overall satisfaction of five for sensation. Jabor et al. [6] showed that, in most cases, the excessive loss of projection over time is the principal cause of dissatisfaction in over 50 percent of women. Eo et al. [21] reported improved projection with the use of excess tissue at mound revision. More recently, Clark et al. [9] reported satisfactory outcomes in 18 cases by designing a composite C-V flap in which a free dermal flap was used from various donor sites (the lateral dog-ears from LD, TRAM, or deep inferior epigastric perforator (DIEP) scars) to augment the C-V flap. There was a high satisfaction of $73 \%$ with the cosmetic appearance after an average follow-up of 36.8 months.In a large study of $252 \mathrm{C}-\mathrm{V}$ flap nipple reconstructions [22], the overall complication rate was reported as $4 \%(0.8 \%$ wound infections and $3.2 \%$ tip necrosis), with $64 \%$ patient satisfaction. Thirty-eight percent of patients, however, wanted greater projection. In the comprehensive study by Sisti et al. [7], complications after nipple reconstruction were $46.9 \%$ after grafting, $7.9 \%$ after local flap reconstruction, and $5.3 \%$ in flaps with autologous graft/alloplastic/allograft augmentation. Complications in areola reconstruction were $10.1 \%$ after grafting and $1.6 \%$ after areola tattooing. The authors concluded that flaps appeared to be more reliable than grafts for nipple reconstruction while tattooing is safer than grafting in areola reconstruction. In our study of those who chose to have tattooing, only one patient complained of tattoo fading three years post procedure. It is not, however, unexpected, since most patients will require touch-up tattooing to maintain colour symmetry [4]. In our study, three patients suffered complete flap loss $(9.1 \%)$. In comparison, Sisti et al. [7] showed an overall complication rate of $7.9 \%$ with total flap loss of $0.7 \%$. The latter, however, examined several different local flap techniques. In our study, of the three patients with complete nipple necrosis, two 
Table 1 Patient demographics, operative details, and outcomes.

\begin{tabular}{|c|c|}
\hline Variable & n (\%), unless otherwise stated \\
\hline Total no. C-V flaps & 33 \\
\hline Age (range, mean, median; yrs) & $40-67,53.5,52$ \\
\hline Follow-up (range (m), mean, median (yrs) & $3-108,4.6,4$ \\
\hline Pre-operative radiotherapy & $7(21)$ \\
\hline Current smoker & $0(0)$ \\
\hline Diabetic & $0(0)$ \\
\hline \multicolumn{2}{|l|}{ Type of reconstruction: } \\
\hline Latissimus dorsi + implant & $29(87.9)$ \\
\hline TRAM & $4(12.1)$ \\
\hline Symmetrisation & $9(27.3)$ \\
\hline Tattooing & $21(63.6)$ \\
\hline Flap loss & $3(9.1)$ \\
\hline
\end{tabular}

Table 2 Patient satisfaction with $\mathrm{C}-\mathrm{V}$ nipple reconstruction scored using a visual analogue scale (IQR).

\begin{tabular}{|c|c|c|}
\hline Parameter & Mean Score & Median Score \\
\hline Shape & 8.3 & $9(8-10)$ \\
\hline Projection & 8.1 & $9(7.5-10)$ \\
\hline Sensation & 5.4 & $5(2-9.5)$ \\
\hline Symmetry & 7.3 & $8.5(6-9.5)$ \\
\hline Overall Satisfaction & 8.2 & $9(8-10)$ \\
\hline Confidence post-procedure & 8.4 & $10(8-10)$ \\
\hline Recommend to other women & 8.9 & $10(8.8-10)$ \\
\hline
\end{tabular}

had undergone nipple piercing post-operatively against medical advice. Those with total nipple loss scored the lowest overall satisfaction but would still have recommended the procedure to other women. There was no association between partial nipple necrosis or nipple loss and previous radiotherapy. No significant difference in projection noted between the reconstructed nipple and the native nipple. Our study, however, included three patients six to twelve weeks postoperative in whom no loss of projection had yet occurred. Our results are in agreement with other publications reporting high satisfaction rates between 62 and $81 \%$ [22-24, 9]. We speculate that the presence of implants under LD flaps might have exerted an additional upward force on the skin surface to maintain better projection. Several studies have shown that, after surgery, the bandage should not com-
Table 3 Specific concerns raised by patients with respect to outcome.

\begin{tabular}{|l|l|l|}
\hline Variable & $\mathbf{n}$ & $\mathbf{\%}$ \\
\hline Completely satisfied & 21 & 63.6 \\
\hline Intractable itch & 1 & 3.0 \\
\hline Tattoo fading & 1 & 3.0 \\
\hline Greater projection desired & 4 & 12.1 \\
\hline Loss of nipple (complete) & 3 & 9.1 \\
\hline Improved waiting time & 1 & 3.0 \\
\hline
\end{tabular}

press the reconstructed nipple since this can contribute to its flattening in the long term $[16,5,25]$.

Loss of projection is a common problem over time [20]. To address this, there have been attempts to augment the C-V flap using acellular dermal matrix [1,2], conchal cartilage [26], or silicon rods [27] with variable complication and success rates. However, the search for an ideal method continues. With the evolution of techniques and technology, newer methods of nipple-areolar complex reconstruction might deliver long-lasting aesthetically acceptable results with minimal morbidity [4].

\section{Conclusion}

The C-V flap provides a straightforward and reliable way of nipple reconstruction that enhances confidence and perception of body image. The satisfaction rate at our unit was high, and the 
long-term outcome of projection was not significantly different from the contralateral breast. It reflected a conscious decision by the operating surgeon to design a larger flap to accommodate later shrinkage. It is consistent with previous recommendations that overcorrection of $25-50 \%$ of the desired result is advisable when using local flaps to prevent loss of projection [7].

Our study was limited by a relatively small sample size from a single institution, and there was potential for observation bias when measuring nipple projection. Despite being a retrospective study, the follow-up period was substantial. Prospective data collection is currently being carried out to assess further longterm outcomes in all patients undergoing this procedure in our unit. The introduction of new techniques to address the loss of projection in some patients provides new opportunities to improve the appearance of the "finishing touch" and focal point of the reconstructed female breast.

\section{Authors' Statements}

The authors declare no conflict of interest.

\section{References}

1. Nahabedian MY. Nipple reconstruction. Clin Plast Surg. 2007;34(1):131-7; abstract vii.

2. Yanaga H. Nipple-areola reconstruction with a dermal-fat flap: technical improvement from rolled auricular cartilage to artificial bone. Plast Reconstr Surg. 2003;112(7):1863-9.

3. Nahabedian MY. Secondary nipple reconstruction using local flaps and AlloDerm. Plast Reconstr Surg. 2005;115(7):2056-61.

4. Nimboriboonporn A, Chuthapisith S. Nipple-areola complex reconstruction. Gland Surg. 2014 Feb;3(1):35-42.

5. Jones G, Bostwick 3rd J. Nipple-areolar reconstruction. Operative Tech Plastic Reconstr Surg.1994; 1:35-8.

6. Jabor MA, Shayani P, Collins DR, Jr., Karas T, Cohen BE. Nipple-areola reconstruction: satisfaction and clinical determinants. Plast Reconstr Surg. 2002;110(2):457-63; discussion 64-5.

7. Sisti A, Grimaldi L, Tassinari J, Cuomo R, Fortezza L, Bocchiotti MA, Roviello F, D'Aniello C, Nisi G. Nipple-areola complex reconstruction techniques: A literature review. Eur J Surg Oncol. 2016; 42(4); 441-65.

8. Winocour S, Saksena A, Oh C, Wu PS, Laungani A, Baltzer H, Saint-Cyr M. A systematic review of comparison of autologous, allogeneic, and synthetic augmentation grafts in nipple reconstruction. Plast Reconstr Surg. 2016 Jan;137(1):14e23e.

9. Elizabeth Clark S, Turton E. The CC-V Flap: A Novel Technique for Augmenting a C-V Nipple Reconstruction Using a Free Dermal Graft. World J Plast Surg. 2014;3(1):8-12.

10. Few JW, Marcus JR, Casas LA, Aitken ME, Redding J. Longterm predictable nipple projection following reconstruction. Plast Reconstr Surg. 1999;104(5):1321-4.

11. Wellisch DK, Schain WS, Noone RB, Little JW, 3rd. The psychological contribution of nipple addition in breast reconstruction. Plast Reconstr Surg. 1987;80(5):699-704.
12. Zhong T, Antony A, Cordeiro P. Surgical outcomes and nipple projection using the modified skate flap for nippleareolar reconstruction in a series of 422 implant reconstructions. Ann Plast Surg. 2009;62(5):591-5.

13. Gurunluoglu R, Shafighi M, Williams SA, Kimm GE. Incorporation of a preexisting scar in the star-flap technique for nipple reconstruction. Ann Plast Surg. 2012;68(1):17-21.

14. Kroll SS. Nipple reconstruction with the double-opposing tab flap. Plast Reconstr Surg. 1999;104(2):511-4; discussion 5-7.

15. Kroll SS, Hamilton S. Nipple reconstruction with the doubleopposing-tab flap. Plast Reconstr Surg. 1989;84(3):520-5.

16. Kroll SS, Reece GP, Miller MJ, Evans GR, Robb GL, Baldwin $\mathrm{BJ}$, et al. Comparison of nipple projection with the modified double-opposing tab and star flaps. Plast Reconstr Surg. 1997;99(6):1602-5.

17. Lesavoy M, Liu TS. The diamond double-opposing V-Y flap: a reliable, simple, and versatile technique for nipple reconstruction. Plast Reconstr Surg.125(6):1643-8.

18. Riccio CA, Zeiderman MR, Chowdhry S, Wilhelmi BJ. Review of nipple reconstruction techniques and introduction of $\mathrm{v}$ to $\mathrm{y}$ technique in a bilateral wise pattern mastectomy or reduction mammaplasty. Eplasty. 2015;15:e11.

19. El-Ali K, Dalal M, Kat CC. Modified C-V flap for nipple reconstruction: our results in 50 patients. J Plast Reconstr Aesthet Surg. 2009;62(8):991-6.

20. Hammond DC, Khuthaila D, Kim J. The skate flap pursestring technique for nipple-areola complex reconstruction. Plast Reconstr Surg. 2007;120(2):399-406.

21. Eo S, Kim SS, Da Lio AL. Nipple reconstruction with C-v flap using dermofat graft. Ann Plast Surg. 2007;58(2):13740.

22. Otterburn DM, Sikora KE, Losken A. An outcome evaluation following postmastectomy nipple reconstruction using the C-V flap technique. Ann Plast Surg. 2010;64(5):574-8.

23. Momoh AO, Colakoglu S, de Blacam C, Yueh JH, Lin SJ, Tobias AM, et al. The impact of nipple reconstruction on patient satisfaction in breast reconstruction. Ann Plast Surg. 2012;69(4):389-93.

24. Valdatta L, Montemurro P, Tamborini F, Fidanza C, Gottardi A, Scamoni S. Our experience of nipple reconstruction using the C-V flap technique: 1-year evaluation. J Plast Reconstr Aesthet Surg. 2009;62(10):1293-8.

25. Weinfeld AB, Somia N, Codner MA. Purse-string nipple areolar reconstruction. Ann Plast Surg. 2008;61(4):364-7.

26. Jones AP, Erdmann M. Projection and patient satisfaction using the "Hamburger" nipple reconstruction technique. J Plast Reconstr Aesthet Surg. 2012;65(2):207-12.

27. Jankau J, Jaskiewicz J, Ankiewicz A. A new method for using a silicone rod for permanent nipple projection after breast reconstruction procedures. Breast. 2011;20(2):124-8. 